\title{
POLA PELAKSANAAN PENDIDIKAN KARAKTER TERHADAP SISWA SEKOLAH DASAR
}

\author{
Murniyetti, Engkizar, dan Fuady Anwar \\ Universitas N egeri Padang (UNP) \\ email: murniyetti@yahoo.co.id
}

\begin{abstract}
A bstrak: Penelitian ini bertujuan untuk mengetahui pola pendidikan karakter terhadap siswa yang dilaksanakan oleh empat sekolah dasar berkategori unggul di Kota Padang Sumatera Barat. Penelitian menggunakan metode kualitatif melalui pendekatan studi kasus (qualitative case study design). Sumber data penelitian diambil dari dua belas orang informan yang terdiri atas kepala sekolah, guru kelas, guru Pendidikan Agama Islam, guru seni dan guru olah raga yang dipilih dari empat sekolah dasar tersebut menggunakan teknik purposive. Data penelitian diambil melalui wawancara secara mendalam (indepth interview) kepada seluruh informan. Hasil penelitian menunjukkan bahwa terdapat delapan tema penting tentang pola pelaksanaan pendidikan karakter efektif yang dilaksanakan terhadap siswa di empat sekolah tersebut. Delapan tema tersebut dilaksanakan melalui: (1) materi pembelajaran; (2) aturan-aturan sekolah (disiplin, peduli lingkungan, tanggung jawab); (3) perlombaan sains antarsiswa (kreatif, gemar membaca, rasa ingin tahu); (4) ajang penghargaan siswa berprestasi (menghargai, kerja keras, demokratis, peduli); (5) peringatan hari kebangsaan (semangat kebangsaan, cinta terhadap tanah air, menghargai, peduli); (6) praktik ibadah dan bimbingan kerohanian (jujur, religius, tanggung jawab); (7) kegiatan pramuka (kreatif, peduli sosial, kerja keras, jujur, bersahabat, cinta damai demokratis); (8) adanya kelas talenta dan musik (kreatif dan bekerja keras, menghargai).
\end{abstract}

Kata Kunci: pola, pendidikan karakter, siswa sekolah dasar

\section{PATTERNS OF CHARACTER EDUCATION OF PRIMARY SCHOOL STUDENTS}

\begin{abstract}
A bstract: This study aims to determine the pattern of character education to students conducted by a superior category of four elementary schools in the city of Padang, West Sumatra. The study used a qualitative method through a case study approach. Sources of data were taken from twelve informants consisting of the principal, classroom teacher, a teacher of Islamic education, art teacher and sports teacher selected from four elementary schools using purposive technique. Data were taken through in-depth interviews (depth interview) to all informants. The results showed that there are eight important themes on the pattern of implementation of effective character education conducted on students in four schools. Eight themes are carried through: (1) the learning materials; (2) the school rules (discipline, care for the environment, responsibility); (3) competition betwen students of science (creative, fond of reading, curiosity); (4) awards outstanding students (respect, hard work, democratic, caring); (5) commemoration day of nationality (the national spirit, love of the homeland, respect, care); (6) the practice of worship and spiritual guidance (honest, religious, responsibility); (7) scouting (creative, social care, hard working, honest, friendly, peace-loving democratic); (8) their talents and music classes (creative and work hard, respect).
\end{abstract}

Keyw ords: pattern, character education, primary school students

\section{PENDAHULUAN}

Dalam usaha mendidik siswa yang berkarakter, terdapat delapan belas nilainilai pendidikan karakter yang mesti ditanamkan oleh seorang guru. Delapan belas pesan karakter tersebut adalah: religius, jujur, toleransi, disiplin, kerja keras, kreatif, mandiri, demokratis, rasa ingin tahu, semangat kebangsaan, cinta tanah air, menghargai prestasi, bersahabat/ komunikatif, cinta damai, gemar membaca, peduli lingkungan, peduli sosial, tanggung jawab (Kesuma, 
2012:32; Amri, 2012: 54; Mulyasa, 2012:35; Daryanto, 2013:43; dan Anggraini, et. al. 2016:76). Pada dasarnya konsep pendidikan karakter bukanlah sesuatu yang baru dalam konsep pendidikan di Indonesia. Buktinya, para pendiri negeri ini secara nyata telah menuangkan nilai-nilai karakter tersebut sebagaimana terlihat jelas pada seluruh sila-sila Pancasila sebagai dasar negara. Menurut Megawangi (2004:35), Wolfgang, et.al. (2006), dan Rawana, et. al. (2011: 76), pendidikan karakter sangat penting untuk pembentukan kepribadian siswa dan diharapkan mampu menjadi fondasi utama dalam membangun manusia Indonesia bertakwa dan siap bersaing di masa mendatang.

Menanamkan nilai-nilai karakter terhadap siswa sebagaimana telah dirumuskan dalam Kurikulum2013merupakan langkah awal untuk memperbaiki tujuan pendidikan di Indonesia (Adisusilo, 2012:36). Begitu juga penanaman pendidikan karakter ternyatamampu mendidik siswa yang unggul dari aspek pengetahuan, cerdas secara emosional, dan kuat dalam keperibadian (Lickona, 2006:93; Milson, et.al. 2010:50; Leslie, 2012:208); dan Darmayanti \& Wibowo, 2014:76).

Menurut beberapa penelitian terdahulu seperti yang dilakukan oleh Lynn \& Arthur (2007) dinyatakan bahwa pendidikan di Indonesia secara umum masih berorientasikan kepada hasil ujian (exam oriented). Oleh karena itu, sudah saatnya sistem pendidikan Indonesia direformasi karena belummampu menjawabkebutuhan zaman. Merujuk kepada hasil penelitian dan pendapat tersebut, maka tentu perlu pembuktian secara empirik akibat dari kurang tepatnya arah pendidikan selama ini sehinggagenerasi sekarang cenderung rapuh, mudah emosi, dan kehilangan karakter sebagai generasi.
Dari berbagai hasil penelitian yang telah penulis himpun, saat ini terdapat tujuh bentuk dekadensi moral generasi muda bangsa. Dekadensi tersebut setidaknya menggambarkan begitu rapuhnya karakter diri generasi muda Indonesia. Pertama, penyalahgunaan narkoba. Ada 3,8 hingga 4,2 juta pengguna narkoba di Indonesia dari kalangan pelajar dan mahasiswa. Dari pengguna narkoba ini $48 \%$ di antaranya adalah pecandu dan 52\% sekadar cobacoba dan pemakai (BN N , 2012). Kedua, pornografi, 64\% pelajar dan mahasiswa belajar seks melalui film porno dan DVD bajakan. A kibatnya 39\% responden dari usia 15-19 tahun dan 25\% usia 20-25 tahun sudah pernah berhubungan seksual (KPAI, 2016). Ketiga, seks bebas, 800 jenis video porno asli produksi dalam negeri, $90 \%$ dari video tersebut diperankan oleh kalangan pelajar dan mahasiswa (KPAI, 2016). Keempat, kasus aborsi, hampir 2,4 juta terjadi setiap tahunnyaatau (700-800 ribu), dan pelakunya adalah kalangan remaja (Komnas HAM. 2016). Kelima, prostitusi, 150.000 anak di bawah usia 18 tahun menjadi pekerja seks, setengah dari pekerja seks tersebut berusia di bawah 18tahun, sedangkan 50.000 di antaranya belum mencapai usia 16 tahun (KPAI, 2016). Keenam, tawuran pelajar dan mahasiswa, pada tahun 2012 sudah terjadi 139 tawuran kasus tawuran, bahkan 12 kasus tersebut menyebabkan kematian, dan pada 2011 dari 339 kasus tawuran menyebabkan 82 anak meninggal dunia (KPA 1, 2016). Ketujuh, geng motor, judi taruhan geng motor berkisar 5 sampai 25 juta rupiah per sekali balapan liar, akibatnya sekitar 60 orang meninggal setiap tahunnya (KPAI, 2016). Itulah beberapa bentuk dekadensi moral yang melanda kalangan generasi muda di Indonesia yang dapat diamati pada Gambar 1. 


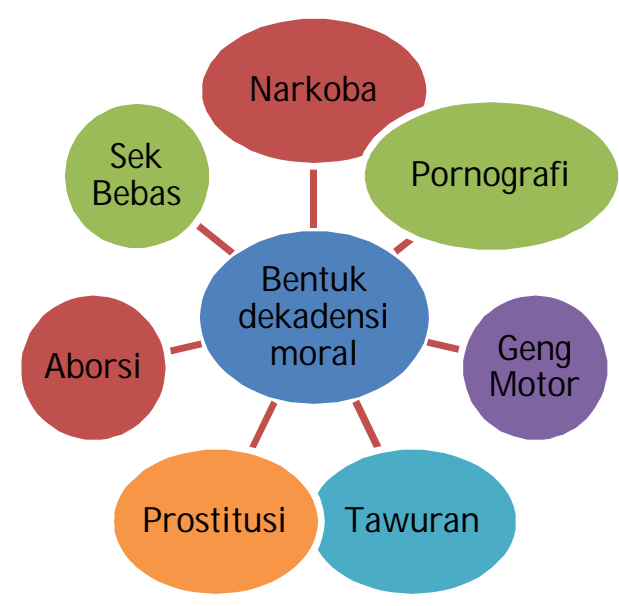

\section{G ambar: 1. Deskripsi Dekadensi Moral G enerasi}

\section{METODE}

Penelitian ini menggunakan metode kualitatif melalui pendekatan studi kasus (qualitative case study design). Menurut Yin (1993:16) dan Denzin \& Lincoln (1994:76) metode ini tepat digunakan apabila peneliti ingin melihat dan mengeksplorasi hasil dari sebuah program atau kegiatan yang telah dilaksanakan. Sedangkan Denzin \& Lincoln (1994:76) dan Bungin (2003:23) menyatakan desain penelitian seperti ini dapat membantu peneliti memahami permasalahan secara dalam dan kompleks. Sumber data penelitian diambil kepada dua puluh orang informan yang terdiri dari kepala sekolah, guru kelas, guru seni, guru olah raga dan guru Pendidikan Agama Islam yang dipilih dari empat sekolah dasar berkategori unggul menggunakan teknik purposive. Menurut Fantana (1994:89), Creswell (2006:54), dan Sugiyono (2014:89) pemilihan informan setidaknya harus mempunyai empat kategori, yaitu: (1) memahami dengan baik permasalahan yang diteliti; (2) masih aktif dalam bidang yang diteliti; (3) mempunyai waktu untuk memberikan informasi kepada peneliti, dan (4) memberikan informasi sesuai dengan fakta yang terjadi di lapangan.
Instrumen penelitian berupa satu set protokol wawancara terstruktur sebagaimana yang dirancang oleh Krueger (1994: 21). Menurut Krueger, agar wawancara tersusun dengan rapi dan informan mudah memahami alur perbincangan, peneliti penting menyusun protokol wawancara dalam beberapa bagian, yaitu pertanyaan pembuka, pengenalan, transisi, kunci, dan pertanyaan penutup. Peneliti tetap harus berperan memandu perbincangan dengan informan sehingga data yang dicari sesuai dengan penelitian (Yin 1994:65). Seluruh data yang dikumpukan melalui wawancaramendalam (indepth interview) selanjutnya dianalisis secara tematik menggunakan software N vivo 8. A nalisis tematik merupakan salah satu cara yang lebih fleksibel untuk mengidentifikasi, menganalisis, dan melaporkan data penelitian kualitatif. Sebelum seluruh data dimasukkan ke dalam alat analisis Nvivo 8, seluruh hasil wawancara dengan informan dilakukan proses transkripsi, kemudian direduksi, dikelompokkan ke dalam sebuah tema untuk dilaporkan dalam bentuk dialog atau verbatim (Virginia Braun \& Victoria Clarke, 2012:23-31).

\section{HASIL DAN PEMBAHASAN}

Berdasarkan hasil wawancara dengan seluruh informan, hasil penelitian se cara nyata mendapati bahwa terdapat de lapan tema penting tentang pola pelaksanaan pendidikan karakter yang dilaksanakan terhadap siswa sekolah dasar di Kota Padang. Delapan tema tersebut dilaksanakan melalui materi pembelajaran, aturanaturan sekolah, perlombaan sains antarsiswa, ajang penghargaan siswa berprestasi, peringatan hari kebangsaan, praktik ibadah harian dan bimbingan kerohanian, kegiatan pramuka, serta adanya kelas talenta dan musik. Lebih jelasnya deskripsi tentang pola pelaksanaan pendidikan karakter terhadap siswa tersebut dapat dilihat pada 
Gambar 2.

Pola pertama yaitu melalui materi pembelajaran. Menurut informan, secara umum cara ini hampir dilaksanakan oleh semua sekolah karena delapan belas nilai pendidikan karakter telah terintegrasi langsung dengan seluruh mata pelajaran. Tema ini disampaikan oleh empat orang kepala sekolah sebagai informan 1, 2, 3, dan 4, se bagaimana terlihat pada petikan wawancara pada Tabel 1.

Pola kedua yaitu melalui aturan-aturan sekolah. Menurut informan, cara ini juga sangat efektif untuk menanamkan nilainilai karakter seperti disiplin, peduli lingkungan, dan tanggung jawab terhadap siswa. Karena secara keseluruhan seluruh siswa harus mempunyai disiplin yang tinggi untuk menaati aturan-aturan sekolah, seperti bagaimana datang tepat waktu ke sekolah, etika terhadap guru, adab berpakain, men- jaga kebersihan, atau bagaimana menjaga kebersihan lingkungan sekolah. Tema ini disampaikan oleh tiga orang guru kelas sebagai informan 5, 6, 7 seperti terlihat pada petikan wawancara pada Tabel 2.

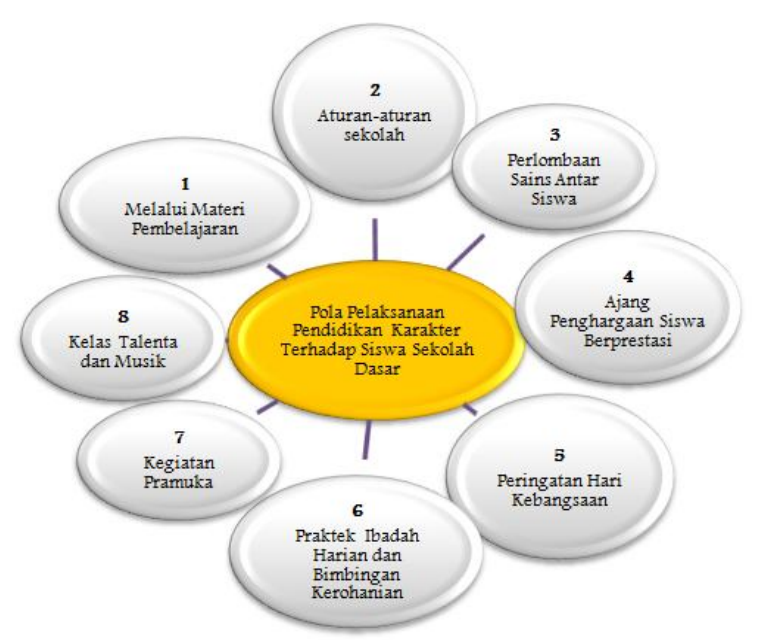

G ambar 2. Deskripsi Pola Pelaksanan

Pendidikan Karakter terhadap Siswa Sekolah Dasar di Kota Padang

\section{Tabel 1. Petikan Wawancara dengan Empat Informan}

\begin{tabular}{ccl}
\hline N o. & Informan & \\
\hline 1. & Informan 1 & $\begin{array}{l}\text { Cara pertama kita lakukan melalui materi pembelajaran, karena memang telah } \\
\text { terintegrasi langsung dengan mata pelajaran,... }\end{array}$ \\
2. Informan 2 & $\begin{array}{l}\text { lya, pertama tentu kita laksanakan melalui bidang mata pelajaran seperti pelajaran } \\
\text { agama, itu masuk indikator religius, pelajaran olah raga ada indikator disiplin dan } \\
\text { mandiri, ... }\end{array}$ \\
3. Informan 3 & $\begin{array}{l}\text { Secara umum tentu kita laksanakan melalui materi pembelajaran di kelas, tapi itu } \\
\text { saja tidak cukup, harus kita kembangkan lagi dalam bentuk kegiatan-kegiatan eks } \\
\text { scool lainnya pak,... }\end{array}$ \\
4. Informan 4 & $\begin{array}{l}\text { Karena kita sekarang menggunakan K-13, tentu secara otomatis itu sudah ter- } \\
\text { integrasi di dalam berbagai silabus, RPP, guru tinggal mengembangkan aja lagi,... }\end{array}$ \\
\hline
\end{tabular}

Tabel 2. Petikan Wawancara tentang Disiplin, Peduli, dan Tanggung Jawab

\begin{tabular}{ccl}
\hline N o. & Informan & \multicolumn{1}{c}{ Petikan Wawancara } \\
\hline 1. & Informan 5 & $\begin{array}{l}\text { A turan-aturan yang dibuat sekolah,...itu akan menanamkan rasa tanggung jawab } \\
\text { dan disiplin diri kepada siswa kita,...saya lihat itu cukup efektif kita terapkan di } \\
\text { setiap sekolah,... }\end{array}$ \\
2. Informan 6 & $\begin{array}{l}\text { Melalui peraturan,...kalau siswa melanggar akan kita sanksi pak! Tujuannya siswa } \\
\text { ada rasa disiplin kepada diri sendiri dan bertanggung jawab... Artinya, mereka tahu } \\
\text { aturan-aturan yang ada. }\end{array}$ \\
3. Informan 7 & $\begin{array}{l}\text { Ada ketentuan-ketentuan yang telah kita sepakati di sekolah, misalnya jangan } \\
\text { buang sampah sembarangan,...kan ada nilai disiplin, peduli lingkungan dan tanggung } \\
\text { jawab di sana pak,... }\end{array}$ \\
\hline
\end{tabular}


Tabel 3. Petikan Wawancara tentang Kreativitas, G emar M embaca, dan Rasa Ingin Tahu

\begin{tabular}{ccl}
\hline N o. & Informan & \multicolumn{1}{c}{ Petikan Wawancara } \\
\hline 1. & Informan 1 & $\begin{array}{l}\text { Kegiatan ini bertujuan untuk memupuk nilai-nilai karakter seperti kreativitas, } \\
\text { terus belajar menerpa diri. }\end{array}$ \\
2. Informan 2 & $\begin{array}{l}\text { Di antara pendidikan karakternya yaitu kreatif, kerja keras, rasa ingin tahu,...gemar } \\
\text { membaca. }\end{array}$ \\
3. Informan 5 & $\begin{array}{l}\text { Kita ingin menumbuhkan nilai karakter keingintahuan yang tinggi terhadap } \\
\text { berbagai disiplin ilmu, harus giat belajar dan serius. }\end{array}$ \\
4. Informan 7 & $\begin{array}{l}\text { Kegiatan ini bertujuan untuk mendidik siswa agar kreatif, rajin membaca, dan rasa } \\
\text { ingi tahu. }\end{array}$ \\
\hline
\end{tabular}

Pola ketiga yaitu melalui perlombaan sains antarsiswa. Menurut informan, perlombaan sains antarsiswa juga rutin dilakukan oleh masing-masing sekolah tersebut. Bahkan, kegiatan tersebut tidak hanya di bidang pelajaran sains, tetapi juga perlombaan yang berkaitan dengan keagamaan, seperti lomba salat, tahfiz Alquran, alasmaul husna, serta perlombaan olahraga, menulispuisi dan cerita, taman, kelas sehat, dan lomba kreativitas. Menurut informan ini merupakan penanaman karakter kreativitas, gemar membaca, dan rasa ingin tahu. Tema ini disampaikan oleh kepala sekolah (sebagai informan 1 dan 2) dan wali kelas (sebagai informan 5 dan 7) seperti terlihat pada Tabel 3.

Pola keempat yaitu melalui ajang penghargaan siswa berprestasi. Menurut informan, cara ini juga merupakan salah satu pola yang dapat dilaksanakan pihak sekolah. Artinya, sekolah mempunyai perhatian terhadap siswa yang mempunyai semangat dan sungguh-sungguh dalam menuntut ilmu. Pesan pendidikan karakter yang terdapat dalam pola ini adalah bagaimana seseorang harus menghargai, demokratis, dan peduli terhadap prestasi orang lain. Di samping itu, pola ini menunjukkan bagaimana seseorang harus mengapresiasi kerja keras seorang siswa yang sungguhsungguh belajar. Tema ini diungkapkan oleh kepala sekolah (sebagai informan 2, 3, dan 4) dan wali kelas (sebagai informan 6 dan 7) seperti terlihat pada petikan wawancara pada Tabel 4.

Pola kelima yaitu melalui peringatan hari kebangsaan. Menurut informan, setiap ada agenda peringatan hari kebangsaan seluruh sekolah dasar selalu memperingatinya, seperti HUT RI dan Hari Pendidkan Nasional. Pelaksanaan ini bertujuan menanamkan nilai karakter pada aspek seperti semangat kebangsaan, cinta terhadap tanah air, menghargai, dan peduli kepada siswa. Tema ini diungkapkan oleh kepala sekolah (sebagai informan 1 dan 2) dan wali kelas (sebagai informan 6 dan 7) seperti terlihat pada petikan wawancara pada Tabel 5 .

Pola keenam yaitu melalui praktik ibadah harian dan bimbingan kerohanian. Berdasarkan observasi penulis selama penelitian, keempat sekolah berkategori unggul yang terlibat dalam penelitian ini sangat memperhatikan kegiatan rutinitas ibadah siswa baik selama berada di sekolah maupun di rumah. Kegiatan praktik ibadah dilaksanakan dengan cara salat berjamaah setiap hari di sekolah. A dapun untuk mengontrol kegiatan ibadah di rumah pihak sekolah telah menyiapkan buku kontrol ibadah harian yang meliputi salat dan membaca Alquran. Di samping itu, keempat sekolah ini juga secara rutin melakukan kegiatan bimbingan kerohanian melaui ceramah agama kepada para siswa. Dua pola tersebutmenurutinforman bertujuan untuk memantapkan pemahaman siswa terhadap 
ajaran Islam seperti akidah, ibadah, dan akhlak sehingga kelak siswa menjadi anakanak yang religius, jujur, dan bertanggung jawab. Temaini disampaikan oleh tiga orang guru agama (sebagai informan 8, 9, dan 10) seperti terlihat pada petikan wawancara pada Tabel 6.

Pola ketujuh yaitu melalui kegiatan pramuka. Menurut informan, cara ini juga merupakan salah satu pola dalam menanamkan nilai-nilai karakter kepada siswa. Karena dengan kegiatan pramuka siswa dapat memiliki nilai-nilai kreatif, peduli sosial, kerja keras, jujur dan bersahabat, cinta da- mai, dan demokratis. Berdasarkan observasi di sekolah-sekolah yang terlibat dalam penelitian ini, kegiatan pramuka merupakan kegiatan ekstrakurikuler favorit bagi siswa di sekolah tersebut. Bahkan, kegiatan pramukadi empat sekolah unggul tersebut merupakan kegiatan pramuka dengan peringkat satu hingga empat terbaik di Kota Padang. Tema ini disampaikan oleh kepala sekolah (informan 1 dan 2), wali kelas (informan 5 dan 6), dan guru olahraga (informan 11), seperti terlihat pada petikan wawancara Tabel 7.

\section{Tabel 4. Petikan Wawancara tentang Kerja Keras}

\begin{tabular}{|c|c|}
\hline No. Informan & Petikan Wawancara \\
\hline 1. Informan 2 & $\begin{array}{l}\text { Ini penting dilaksanakan sehingga tertanam sikap dan nilai-nilai karakter } \\
\text { menahargai kepedulian keria keras, }\end{array}$ \\
\hline 2. Informan 3 & $\begin{array}{l}\text { A jang-ajang seperti ini perlu dilaksanakan setiap sekolah, karena ada nilai-nilai } \\
\text { karakter rajin, semangat, mengakui kel ebi han,... }\end{array}$ \\
\hline & $\begin{array}{l}\text { Biasanya masing-masing melaksanakan kegiatan ini, pesan karakternya adalah } \\
\text { bekerja keras, menghargai, demokratis. }\end{array}$ \\
\hline & $\begin{array}{l}\text { Sekolah kita selalu adakan kegiatan setiap semester,... ada nilai menghargai, } \\
\text { kepedulian. }\end{array}$ \\
\hline 5. Informan 7 & $\begin{array}{l}\text { A jang ini penting!,.. ada nilai-nilai demokratis, menghargai, dan peduli yang kita } \\
\text { tanamkan kepada siswa. }\end{array}$ \\
\hline
\end{tabular}

\section{Tabel 5. Petikan Wawancara tentang Nasionalisme, M enghargai, dan Peduli}

\begin{tabular}{c}
\hline N o. Informan \\
\hline 1. Informan 1 A danya peringatan tersebut akan menanamkan sikap cinta tanah air, semangat \\
bernegara, peduli dan menghargai.
\end{tabular}

Tabel 6. Petikan Wawancara tentang Religius, Jujur, dan Tanggung Jawab

\begin{tabular}{cl}
\hline N o. Informan & \multicolumn{1}{c}{ Petikan Wawancara } \\
\hline 1. Informan 8 & $\begin{array}{l}\text { Melalui praktik ibadah harian dan bimbingan kerohanian, seperti salat berja- } \\
\text { maah, berdoa, membaca A lquran, ceramah agama akan menanamkan karakter } \\
\text { religius, jujur, bertanggung jawab kepada diri siswa kelak. }\end{array}$ \\
2. Informan 9 $9 \begin{array}{l}\text { Di sekolah ini ada program praktik ibadah dan bimbingan rohani Islam bagi } \\
\text { siswa. Dua program ini bertujuan agar siswa kita mempunyai karakter yang jujur } \\
\text { dan religius. }\end{array}$ \\
3. Informan 10 \\
$\begin{array}{l}\text { Penanaman nilai karakter melalui kegiatan ibadah penting dilaksanakan untuk } \\
\text { menanamkan sifat religius dan bertanggung jawab kepada anak. }\end{array}$ \\
\hline
\end{tabular}


Tabel 7. Petikan Wawancara tentang Kerja Keras, Damai, Peduli, dan D emokratis

\begin{tabular}{cl}
\hline N o. Informan & \multicolumn{1}{c}{ Petikan Wawancara } \\
\hline 1. Informan 1 & $\begin{array}{l}\text { Melalui pramuka siswa belajar untuk bersosial, bekerja keras, jujur, persahabatan, } \\
\text { dan demokratis. }\end{array}$ \\
2. Informan 2 & $\begin{array}{l}\text { Kegiatan pramuka paling digemari oleh siswa di sekolah ini. Di pramuka } \\
\text { mereka belajar demokratis, kepedulian, dan kejujuran. }\end{array}$ \\
3. Informan 5 & $\begin{array}{l}\text { Kegiatan pramuka juga salah satu cara menanamkan pendidikan karakter. Kare } \\
\text { na dengan pramuka siswa dilatih untuk bekerja keras, jujur, perdamaian, dan de } \\
\text { mokratis. Pramuka di sekolah ini merupakan terbaik di Kota Padang ini. }\end{array}$ \\
4. Informan 6 & $\begin{array}{l}\text { Melalui kegiatan pramuka siswa akan dilatih untuk bekerja keras, suka perdamai- } \\
\text { an, dan belajar demokratis. }\end{array}$ \\
5. Informan 11 & $\begin{array}{l}\text { Melalui kegiatan pramuka siswa akan dilatih untuk bersosial, bekerja keras, jujur, } \\
\text { persahabatan, dan demokratis. }\end{array}$ \\
\hline
\end{tabular}

Tabel 8. Petikan Wawancara tentang Kreatif, Kerja Keras, dan M enghargai

\begin{tabular}{cl}
\hline N o. Informan & \multicolumn{1}{c}{ Petikan Wawancara } \\
\hline 1. Informan 1 & $\begin{array}{l}\text { Ada ciri khas lain di sekolah ini dalam mendidik karakter ana. Kita sediakan } \\
\text { kelas bakat dan musik bagi siswa yang mempunyai bakat sehingga mereka da- } \\
\text { pat mengekplorasi bakat tersebut. Pesan karakternya adalah ada kreativitas, dan } \\
\text { bekerja keras. }\end{array}$ \\
2. Informan 2 & $\begin{array}{l}\text { Sebagai guru kita juga perlu menyediakan kelas bakat dan musik bagi siswa yang } \\
\text { mempunyai talenta-talenta lebih. Kita ingin menyampaikan pesan karakter bahwa } \\
\text { siswajuga dihargai untuk mengembangkan kreativitas-nya. }\end{array}$ \\
3. Informan 6 6 & $\begin{array}{l}\text { Di sekolah ini memang senagaja kita buka kelas bakat dan seni, sehingga siswa } \\
\text { juga merasa dihargai, dan kreatif mereka dapat dikembangkan }\end{array}$ \\
4. Informan 12 & $\begin{array}{l}\text { Tujuan dibukanya kelas bakat dan seni musik adalah agar siswa belajar mengem- } \\
\text { bangkan kreativitas mau belajar lebih giat lagi. }\end{array}$ \\
\hline
\end{tabular}

Pola kedelapan yaitu melalui adanya kelas talenta dan musik. Pola kedelapan ini tidak banyak penulis temui di sekolah-sekolah dasar di Kota Padang. Namun, be berapa sekolah unggul yang terlibat dalam penelitian ini telah membuka kelas talenta dan kelas musik untuk mengembangkan bakat para siswa. M enurut beberapa orang informan, pola ini dapat menanamkan nilai-nilai karakter kreatif, bekerja keras, dan menghargai kepada siswa. Di samping itu, kelas bakat dan musik ini juga sebagai salah satu cara memperkenalkan sekolah tersebut dari aspek yang berbeda kepada masyarakat luas. Tema ini disampaikan oleh kepala sekolah (informan 1 dan 2), wali kelas (informan 6), dan guru seni (informan
12) seperti terlihat pada petikan wawancara Tabel 8.

Padaprinsipnya, pola pelaksanaan dalammenanamkan nilai-nilai pendidikan karakter terhadap siswa di sekolah tidak diatur secara baku dan mutlak. Namun, yang terpenting adalah bagaimana nilai-nilai karakter tersebut sampai, dipahami, tertanam, dan diharapkan menjadi perilaku permanen dalam setiap diri siswa. Dengan mencermati hasil penelitian ini, maka terlihat jelas delapan pola pelaksanaan pendidikan karakter pada empat sekolah berkategori unggul sebagaimanaterdapat dalam hasil penelitian ini. Pendekatan pelaksanaan pendidikan karakter dapat dilakukan dengan berbagai cara. MenurutSmith (2013:352), pola pendidikan karakter yang bertumpu kepada 
strategi tunggal sudah tidak memadai untuk menyampaikan nilai-nilai karakter. Hasil penelitian ini didukung oleh penelitian Thambusamy \& Elier (2013), Husaini Usman (2009), Ekowarni (2010), Lickona (2014), dan Koesoema (2012) yang mendapati bahwa di antara keberhasilan penerapan nilainilai karakter kepada siswa dapat dilaksanakan melalui multipendekatan baik melalui pembelajaran di kelas (instruksional) maupun kegiatan di luar kelas (noninstruksional).

Sesungguhnya pelaksanaan pendidikan karakter di sekolah bertujuan untuk menghasilkan siswa yang mampu berperilaku sesuai dengan atauran serta norma agama, social, dan budaya. Lickona (2014:89) menyatakan, "Character education programs have gained increasing interest in the past decade and are designed to produce students who arethoughtful, ethical, morally responsible, community oriented, and selfdisciplined." Kebaikan perilaku yang dimaksud diwujudkan dalam kepribadian yang bijaksana, beretika, bermoral, bertanggung jawab, yang berorientasi pada masyarakat, dan disiplin diri.

Sekolah merupakan salah satu di antara sarana yang cukup efektif untuk melaksanakan, mengembangkan sekaligus mensukseskan agenda pendidikan karakter secara nasional karena dunia sekolah merupakan tempat kedua bagi siswa menghabiskan waktu setelah di rumah tangga. Artinya, pola dan disain pelaksanaan pendidikan karakter yang dilaksanakan sebuah sekolah mempunyai peranan yang sangat besar dalam menentukan keberhasilan pendidikan karakter. Hasil penelitian Roslind \& Elier (2013), dan Saputro \& Soeharto (2015) mendapati pelaksanaan pendidikan karakter di sekolah perlu dirancang secara baik dan didukung oleh pihak sekolah dalam berbagai bentuk kegiatan. Oleh sebab itu, menurut penulis delapan pola pelaksanaan pendidikan karakter yang telah terlaksana di empat sekolah dasar Kota Padang melalui materi pembelajaran, aturanaturan sekolah, perlombaan sains antarsiswa, ajang penghargaan siswa berprestasi, peringatan hari kebangsaan, praktik ibadah harian, bimbingan kerohanian, kegiatan pramuka, dan adanya kelas talenta dan musik dipandang sudah tepat, hanya saja pola-pola tersebut perlu dievaluasi dan dikembangkan lagi.

Hasil penelitian juga telah menggambarkan bahwa penerapan berbagai pola pendidikan karakter terhadap siswa sekolah dasar di Kota Padang setidaknya telah dapat menyampaikan delapan belas indikator pendidikan karakter menuju siswa yang re ligius, jujur, toleransi, disiplin, kerja keras, kreatif, mandiri, demokratis, rasa ingin tahu, semangat kebangsaan, cinta tanah air, menghargai prestasi, bersahabat atau komunikatif, cinta damai, gemar membaca, peduli lingkungan, peduli sosial, dan tanggung jawab.

Bagi pihak sekolah, pentingnya pelaksanaan pendidikan karakter untuk siswa bukan hanya sekedar memenuhi tugas dan tanggung jawab dalam rangka menjalankan kurikulum yang telah dibebankan, akan tetapi penanaman nilai-nilai karakter merupakan penyeimbang atas pengetahuan yang dimiliki oleh seorang siswa. Nilai karakter merupakan salah satu upaya dalam membentuk siswa secara utuh (holistik), yaitu mengembangkan siswa dari aspek fisik, emosi, sosial, kreativitas, dan intelektual secara optimal (Beachum, et. al. 2015). Harapannya, dengan nilai-nilai karakter tersebut siswa dapat memanfaatkan pengetahuan yang dimilikinya untuk halhal yang positif (Masnur, 2013: 23).

Sedangkan Berkowitz \& Hoppe(2009: 133), dan Russell \& Waters (2014:163) meng- 
ungkapkan bahwa pendidikan karakter diharapkan dapat mengatasi krisis yang terjadi dalam karakter masyarakat global dan mengembangkan potensi manusia secara optimal serta mengembangkan pola pikir dan perilaku siswa yang bertanggung jawab atas pelaksanaan peran agama, sosial, masyarakat, dan sebagai warga negara. Sebagaimana juga dinyatakan oleh Lickona (2006:56) dan Walker, et. al. (2013:84) bahwa karakter terdiri atas nilai-nilai kebajikan yang digunakan sebagai pedoman daIam berperilaku. Karakter sebagai kepribadian yang terbentuk dari kebajikan digunakan sebagai landasan dalam berpikir, bersikap, dan bertindak.

\section{PENUTUP}

Pentingnya pendidikan karakter bagi siswa merupakan suatu keperluan yang tidak terbantahkan lagi. Tidak ada aturan baku dan mutlak bagaimana cara melaksanakan pendidikan karakter. Namun, sekolah dituntut mendisain secara baik dan sungguh-sungguh dengan berbagai pola sehingga nilai-nilai karakter tersebut dapat menjadi perilaku permanen bagi siswa di kemudian hari. Berbagai pola yang telah dilakukan oleh sekolah dasar di Kota Padang tentu dapat dijadikan acuan bagi sekolah lainnya. Pola-pola lain masih dapat dicoba sesuai dengan corak dan karakteristik sekolah dan siswanya. Namun demikian, tujuan pendidikan karakter tetap sama, yakni mengantarkan siswa mempunyai ke pribadian dan nilai-nilai karakter mulia, seperti religius, jujur, toleransi, disiplin, kerja keras, kreatif, mandiri, demokratis, rasa ingin tahu, semangat kebangsaan, cinta tanah air, menghargai prestasi, bersahabat atau komunikatif, cinta damai, gemar membaca, peduli lingkungan, peduli sosial, dan tanggung jawab.

\section{UCAPAN TERIMA KASIH}

Terselesaikannya penelitian serta tulisan ini, di samping atas upaya dan kerja keras kami peneliti dan penulis, tentu juga berkat bantuan dari berbagai pihak. $\mathrm{Pe}$ nulis menyampaikan ucapan terima kasih kepada Dr. Marzuki selaku Ketua Dewan Redaksi Jurnal Pendidikan Karakter yang menerima dan telah banyak memberikan masukan dan arahan demi terselesaikannya tulisan ini.

\section{DAFTAR PUSTAKA}

Adisusilo, SutarjoJ.R. 2012. Pembelajaran N iIai Karakter. Depok: PT Raja Grafindo Persada.

Andrew J. Milson \& Lisa, M ,. Mehlig. 2010. “Elementary School Teachers' Sense of Efficacy for Character Education". The ournal of Educational Research, Vol. 96, No. 1, hlm. 47-53.

Amri, Ulil Syafri. 2012. Pendidikan Karakter Berbasis AI-Qur'an. Jakarta: Rajawali Pers.

Anggraini, et.al. 2016. “The Implementation of Character Education Model Based on Empowerment Theatre for Primary School Students". Journal of Education and Practice, Vol. 7, No. 1, hlm. 26-29.

Badan Narkotika Nasional. 2012. Pengguna $\mathrm{N}$ arkoba di Kalangan Pelajar dan M ahasiswa. Diunduh dari http:// www.bnn.go.id, diakses 12 Juni. 2016.

Beachum, Floyd D., et.al. 2015. "Support and Importance Of Character Education: PreServiceTeacher Perceptions". J ournal of Education and Practice, Vol. 11, No. 3, hIm. 34-42.

Berkowit, Marvin W. \& Hoppe, Mary A. 2009. "Character Education and Gif- 
tedness". Journal High A bility Studies, Vol. 20, No. 2, hlm. 131-142.

Brian H. Smith. 2013. "School-based Character Education in the United States". Journal Childhood Education, Vol. 89, No. 6, hlm. 350-355.

Bungin, B. 2003. A nalisis D ata Penelitian Kualitatif: Pemahaman Filosofis dan M etodologis Ke Arah Pengusaan M odel A plikasi. Jakarta: P.T. Raja Grafindo Persada.

Creswell, J. W. 2006. Research D esign: Q ualitative And Quantitave Approaches. Thousand Oaks: SA GE Publication.

Darmayanti, S., \& Wibowo, U. 2014. “Evaluasi Program Pendidikan Karakter di Sekolah Dasar Kabupaten Kulon Progo". Jurnal Prima Edukasia, Vol. 2, No. 2, hlm. 223-234.

Darmiyati, dkk. 2010. "Pengembangan Model Pendidikan Karakter Terintegrasi Dalam Pembelajaran Bidang Studi di Sekolah Dasar". Cakrawala Pendidikan, Vol. 2. No. 4, hlm. 22-24.

Daryanto, dkk. 2013. Implementasi Pendidikan Karakter di Sekolah. Yogyakarta: Gava Media.

Denzin, NK \& Lincoln, YS. 1994. Introduction: Entering the Field of $\mathrm{Q}$ ualitative $\mathrm{Re}$ search. Thousand Oaks: Sage Publications.

Ending, Ekowarni. 2010. Pengembangan Nilai-nilai Luhur Budi Pekerti sebagai Karakter Bangsa. Cakrawala Pendidikan Edisi Dies Natalis UNY.

Fantana, A. \& Frey, J.S. 1994. “Interviewing: The art of science". DIm Denzin, N.K. \& Lincoln, Y.S. (Eds.). H andbook of Q ualitative Research. Thousand Oaks: Sage Publication.
Kesuma, Dharma. 2012. Pendidikan Karakter Kajian Teori dan Praktik di Sekolah. Bandung: PT Remaja Rosdakarya.

Koesoema, Doni A. 2007. Pendidikan Karakter Strategi M endidik A nak di Z aman Global. Jakarta: Grasindo.

Komisi Nasional Hak Asasi Manusia. 2016. A borsi di Kalangan Remaja di Indonesia. Diunduh dari http// www.komnasham.go.id. diakses 24 Oktober 2016.

Komisi Perlindungan Anak Indonesia. 2016. Berbagai Bentuk D ekadensi M oral Generasi M uda. Diunduh dari http:/ / www.kpai.go.id. Diakses 28 September 2016.

Krueger, R.A. 1994. Focus Group: A Practical Guide For A pplied Research. Ed. Ke-2. Thousand Oaks: Sage Publications.

Leslie, K,. Grier. 2012. "Character, SocialEmotional, and Academic Outcomes Among Underachieving Elementary School Students". Journal of Education for Students Placed at Risk (JESPAR), Vol. 17, No. 3, hlm. 201-216.

Lickona, Thomas. 2006. “Eleven Principles of Effective Character Education". Journal of Moral Education, Vol. 25, No. 1, hlm. 93-100.

Lickona, Thomas. 2014. “Educating for Character". J ournal of M oral Education, Vol. 13, No. 3, hlm. 89-97.

Lincoln, Y. \& Guba, E. G. 1994. “Competing Paradigms in Qualitative Research". DIm Denzin, N.K. \& Lincoln, Y.S. (Eds.). $\mathrm{H}$ andbook of Q ual itative Research. Thousand Oaks: Sage Publication.

Lynn, Revell \& James, Arthur. 2007. "Character Education In Schools and The Education of Teachers". J ournal of M 0ral Education, Vol. 36, No. 1, hlm. 7992. 
Megawangi, Ratna. 2004. Pendidikan Karakter Solusi Tepat untukM embangun Bangsa. Jakarta: Indonesia Heritage Fondation.

Mulyasa, E. 2012. M anajemen Pendidikan Karakter. Jakarta: Bumi Aksara.

Muslich, Masnur. 2013. Pendidikan Karakter M enjawabT antangan Krisis M ultidimensional. Jakarta: Bumi A ksara.

Rawana, J.R.E., Franks, J.L., Brownlee, K., Rawana, E.P. \& Neckoway, R. 2011. "The Aplication of a Strength-Based Approach of Students' Behaviours to the Development of a Character Education Curriculumfor Elementary and Secondary School". Journal of Education Thought, Vol. 45, No. 16, hlm. 127-144.

Roslind, Thambusamy \& Adzura, A. Elier. 2013. "Shaping the Bamboo From the Shoot: Elementary Level Character Education in Malaysia". Journal Childhood Education, Vol. 89, No. 6, hlm. 368-378.

Saputro, H., \& Soeharto, S. 2015. “Pengembangan Media Komik Berbasis Pendidikan Karakter pada Pembelajaran Tematik-IntegratifKelasIV SD".Jurnal Prima Edukasia, Vol. 3, No. 1, hlm. 6172.

Sugiyono. 2014. M emahami Penelitian Kualitatif. Bandung: CV. Alfabeta.
Usman, Husaini. 2009. M anajemen: Teori, Praktik dan Riset Pendidikan. Jakarta: Bumi Aksara.

Virginia Braun \& Victoria Clarke. 2012. “Using Thematic Analysis in Psychology, Qualitative Research in Psychology". Jounal M etodologi Recearch in Psykologi, Vol. 3, No. 2, hlm. 77-101.

Walker, David I., et.al. 2013. “Towards a New Era of Character Education in Theory and in Practice". Journal Educational Review, Vol. 67, No 1, hlm. 7996.

William, B. Russell III \& Stewart, Waters. 2014. "Developing Character in Middle School Students: A Cinematic A pproach". Journal the Clearing H ouse, Vol. 87, No. 4, hlm. 161-167.

Wolfgang, Althof \& Berkowitz, Marvin W. 2006. "The Moral Roots of Citizenship and Citizenship Education". J ournal of M oral Education, Vol. 35, No. 4, hlm. 495-518.

Yin, R. K. 1993.Applications of Case Study Research. Newbury Park: Sage Publications.

Zuchdi. 2006. “Pendidikan Karakter melalui Pengembangan Keterampilan Hidup dalam Kurikulum Persekolahan. Laporan Penelitian Hibah Pasca, 20052006. Yogyakarta: Lembaga Penelitian UNY. 